\title{
A CONSTRUCCÃO ESCOLAR DA HIPERATIVIDADE: CONTROVÉRSIAS ACERCA DO TRABALHO DE DIAGNÓSTICO E INTERVENÇÃO EM TORNO DE JOVENS COM PHDA EM ESCOLAS PORTUGUESAS
}

\author{
João Feijão ${ }^{1}$ \\ Nélia Freitas ${ }^{2}$
}

\section{RESUMO}

Este artigo resulta de um trabalho de pesquisa em torno do tratamento e do diagnóstico da Perturbação de Hiperatividade e Défice de Atenção (PHDA) em jovens nas escolas portuguesas. Mais concretamente, procurámos compreender a construção escolar que é feita pelos profissionais de ensino e pelos técnicos educativos sobre estes alunos, como é realizado o trabalho de diagnóstico e intervenção quotidiana sobre os mesmos, bem como identificar os acordos e desacordos existentes entre os professores e os técnicos quando estes justificam e defendem o seu ponto de vista sobre a melhor forma de intervir sobre cada caso. A abordagem teórica privilegiada é a sociologia pragmática de Luc Boltanski e Laurent Thévenot, que nos permite perceber como os atores sociais experienciam as situações em que estão envolvidos, concebendo-os como competentes e capazes de emitir pontos de vista críticos para ajuizar situações e expressar os seus sentimentos de (in)justiça. Os principais resultados, obtidos nesta pesquisa, refletem um aumento dos diagnósticos desta patologia, existindo contudo algumas dúvidas na qualidade e fiabilidade dos mesmos. Foi possível concluir igualmente que a perceção dos professores se altera quando o aluno é diagnosticado, praticando-se uma inclusão escolar depois da exclusão e da construção de uma identidade deteriorada no contexto da sala de aula. Relativamente às formas de tratamento desta patologia no contexto escolar registaram-se algumas críticas ferozes à comunidade cientifica pela inexistência de consensos e definição do que é um aluno hiperativo e/ou com défice de atenção. Em relação à sua relevância social e científica, este estudo permite uma compreensão mais alargada da realidade em que estes jovens vivem no contexto escolar, sendo útil tanto para professores, como para técnicos educativos, familiares com filhos com o mesmo problema e para investigadores que se dediquem à problemática da regulação de comportamentos e da reparação de alunos com identidades deterioradas nas escolas.

Palavras-chave: PHDA. Escolas. Diagnóstico. Intervenção. Professores. Técnicos Educativos.

${ }^{1}$ Sociólogo. Estudante de Doutoramento em Sociologia, com especialidade em Sociologia da Educação, do Conhecimento e da Cultura na FCSH-UNL. Investigador colaborador no Centro Interdisciplinar em Ciências Sociais da Universidade Nova de Lisboa no grupo de trabalho "Ação Pública e Desigualdades Sociais". Faculdade de Ciências Sociais e Humanas da Universidade Nova de Lisboa/Centro Interdisciplinar de Ciências Sociais da Universidade Nova de Lisboa (CICS.NOVA). E-mail: joaomfeijao@gmail.com

${ }^{2}$ Socióloga. Mestre em Sociologia com especialidade em comunidades e dinâmicas sociais. Faculdade de Ciências Sociais e Humanas da Universidade Nova de Lisboa. E-mail: neliafreitas@live.com.pt 


\section{ABSTRACT}

This article is the result of a fieldwork research on the diagnosis and treatment of Attention-Deficit Hyperactivity Disorder (ADHD) in young people at Portuguese Schools. Concretely, we have tried to understand the school construction made by teachers and educational experts about these students, how the everyday work of diagnosis and treatment is done by teachers and educational experts and identify the agreements and disagreement dynamics between both educative professionals, when they justify and defend their views on how best to intervene in each case. Our theoretical approach is based on the pragmatic sociology of Luc Boltanski and Laurent Thévenot which enables to understand how the social actors experience the situation in which they are involved, conceiving them as competent and capable of express their own critical points of view to judge the situations and show their own feelings of justice. The main results obtained in this research reflect a significant increase in diagnosis of ADHD, although that diagnosis suggests some doubts concerning its quality and reliability. It was also possible to conclude that the teachers' perception change when the student is diagnosed and so they practice a school inclusive after school exclusion and after the construction of a spoiled identity in classroom. Relatively to the ways of treatment of this pathology in school, we note some criticism to scientific community concerning the lack of consensus and definition of what is a student with attention-deficit and hyperactivity disorder. Regarding this article's scientific an social relevance, this study will allow deeper understanding of the reality that these young people live in school context, it will be useful for teachers and educational experts as well to the families with children with the same problems, and also may interest social researchers that make their work about the regulation and the repair of students' behavior with spoiled identities at schools.

Keywords: ADHD. Schools. Diagnosis. Intervention. Teachers. Educational Experts. 


\section{Introdução}

O presente artigo resulta de uma pesquisa intitulada "Crianças e Jovens com Perturbação de Hiperatividade e Défice de Atenção: controvérsias em torno do diagnóstico e do tratamento", desenvolvida no âmbito do mestrado em Sociologia, na especialidade de Comunidades e Dinâmicas Sociais (FREITAS, 2013). Como objetivo geral, procurouse perceber como profissionais do ensino e da saúde se situam e agem face a novas práticas de regulação dos comportamentos e dos corpos no contexto das salas de aula e nos pátios da escola.

Especificamente, tentou-se compreender como esses profissionais procedem na sinalização de alunos com Perturbação de Hiperatividade e Défice de Atenção (PHDA), como são encaminhados os casos para os especialistas e técnicos, perceber quem são os intervenientes no diagnóstico, entender como é feito o plano de intervenção sobre os jovens e como é feita a monitorização dos casos. Foi igualmente pretensão desta pesquisa indagar sobre os acordos e desacordos que existem entre professores e especialistas quanto à melhor forma de sinalizar, diagnosticar, encaminhar e fazer o tratamento dos alunos com PHDA. Deste modo, pudemos perceber e interpretar as convergências e divergências que existem entre profissionais e as diferentes formas de intervir em torno deste problema. Tentámos igualmente apreender o quotidiano de trabalho destes profissionais, sobretudo no aspeto do trabalho em equipa, da natureza do seu trabalho de intervenção e das estratégias que desenvolvem, mas também da forma como se articulam com as famílias dos alunos com PHDA. Foi ainda nosso objetivo tentar compreender as críticas que estes atores que trabalham nas escolas fazem a outros atores que também têm uma atuação junto destas crianças (famílias, comunidade médica e científica).

Em termos de abordagem teórica, esta pesquisa foi inspirada pelos contributos teóricos do estruturalismo de Michel Foucault (1996), sobretudo no aspeto da disciplina como ferramenta para a docilização dos corpos. Também Émile Durkheim (1984) constituiu, com os seus textos clássicos sobre educação, uma fonte de inspiração com as ideias de como o professor deveria incutir a disciplina e a regulação escolar nos alunos. Esta pesquisa foi também inspirada pelo interacionismo simbólico de Erving Goffman, sobretudo pelas suas ideias sobre o conceito de reparação, no seu livro sobre o estudo das instituições totais (GOFFMAN, 2008), mas também através da sua ideia de 
estigma e de manipulação de identidades deterioradas (GOFFMAN, 1984).

Numa pesquisa recente que está a ser desenvolvida por um de nós (FEIJÃO, 2014), no âmbito do doutoramento em sociologia, relativa ao estudo da reparação das turbulências na escola por professores e profissionais de mediação escolar, temos vindo a observar as potencialidades hermenêuticas da perspetiva da sociologia pragmática aquando do estudo das dinâmicas inerentes aos fenómenos socioeducativos. A perspetiva da sociologia pragmática tende a conceber os atores como seres competentes, isto é, capazes de avaliar as situações em que se inserem e emitir pontos de vista críticos em relação a essas situações, engendrando novas formas de se envolverem na situação e produzirem o comum (BOLTANSKI e THÉVENOT, 1991).

Consideramos que, embora as perspetivas estruturalistas e interaccionistas tenham permitido caracterizar e opor uma escola do passado (repressiva e disciplinadora) e uma escola do presente (inclusiva e reparadora), elas não conseguiram cobrir e sustentar a interpretação das controvérsias, isto é, acordos e desacordos dos diferentes profissionais, relativamente às formas de diagnóstico e tratamento de alunos com Perturbação de Hiperatividade e Défice de Atenção. Assim, tendo em conta este objetivo, julgamos ser pertinente o recurso à sociologia pragmática para interpretação dos dados.

Em termos metodológicos, optou-se por uma pesquisa de tipo qualitativo com recurso a entrevistas semiestruturadas. Foram realizadas entrevistas em agrupamentos de escolas na região de Lisboa com incidência nos $2^{\circ}$ e $3^{\circ}$ Ciclos do Ensino Básico (do $5^{\circ}$ até ao $9^{\circ}$ ano). Decidiu-se selecionar dois agrupamentos de escolas em que os atores sociais a serem entrevistados estivessem a trabalhar com alunos com diagnóstico clínico de Perturbação de Hiperatividade e Défice de Atenção ou em que houvesse sinalizações e diagnósticos realizados pelos profissionais de ensinos e pelos técnicos de saúde escolares. No total, foram realizadas treze entrevistas: seis a Diretores de Turma/Professores do Ensino Regular; cinco entrevistas a Professores de Ensino Especial; uma entrevista a uma Psicóloga Clínica e uma entrevista a um Terapeuta Psicomotricista, ambos a prestarem serviços nas escolas. Foram entrevistados quatro profissionais do sexo masculino e nove do sexo feminino, com idades compreendidas entre os vinte e cinco e os cinquenta e três anos de idade, com uma 
experiência profissional de três a trinta e três anos e com habilitações literárias de licenciatura e mestrado.

Os principais resultados, obtidos nesta pesquisa, refletem um aumento dos diagnósticos desta patologia, existindo contudo algumas dúvidas na qualidade e fiabilidade dos mesmos. Foi possível concluir igualmente que a perceção dos professores se altera quando o aluno é diagnosticado, praticando-se uma inclusão escolar depois da exclusão e da construção de uma identidade deteriorada no contexto da sala de aula. Relativamente às formas de tratamento desta patologia no contexto escolar, registaram-se algumas críticas ferozes à comunidade cientifica pela inexistência de consensos e definição do que é um aluno hiperativo e/ou com défice de atenção.

Este texto foi dividido em quatro partes. Na primeira parte, fazemos uma primeira abordagem à Perturbação da Hiperatividade e Défice de Atenção, tal como tem sido definida por algumas associações - como a Associação Portuguesa da Criança Hiperativa e a Associação Americana de Psiquiatria - e introduzimos algumas controvérsias em torno do diagnóstico e do tratamento desta perturbação. Na segunda parte, explana-se como têm sido percecionados e regulados os comportamentos dos jovens que sofrem de PHDA nas escolas, destacando a adesão da instituição escolar ao princípio da inclusão e a criação de dispositivos para acompanhar estes alunos. Na terceira parte, fazemos uma revisão da literatura sobre a temática, verificandose a predominância dos contributos das ciências da educação no estudo das perceções e atuações dos professores acerca dos alunos com PHDA. Na quarta parte deste artigo, expomos os resultados da pesquisa desenvolvida em torno das controvérsias acerca do diagnóstico e tratamento de jovens com Perturbação da Hiperatividade e Défice de Atenção nas escolas portuguesas. Por fim, tecemos as nossas considerações finais sobre esta pesquisa.

\section{A Perturbação de Hiperatividade e Défice de Atenção}

A Associação Portuguesa da Criança Hiperativa ${ }^{3}$ (2012) estima que a Perturbação de Hiperatividade e Défice de Atenção afete cerca de 3\%

${ }^{3}$ Associação Portuguesa da Criança Hiperativa -

http://www.apdch.net/associacao.html 
a $7 \%$ das crianças em idade escolar, estimando-se que exista cerca de 35 a 50 mil crianças com esta perturbação, e sendo mais comum nos rapazes do que nas raparigas. Como refere essa Associação,

Os casos de hiperatividade infantil estão a aumentar. Uma pesquisa que envolveu 500 crianças de todo o país com queixas de hiperatividade, realizada pelo Instituto da Inteligência, revela que $57 \%$ das causas estão relacionadas com o meio de vida familiar e o estilo de vida dos pais e $43 \%$ com a escola e o stress (APCH, 2012: 1) ${ }^{4}$.

Segundo Lourenço (2009), a PHDA pode ser definida como um distúrbio de desenvolvimento que se caracteriza por graus de desenvolvimento de excessiva desatenção, excesso de atividade psicomotora e impulsividade, ocorrendo geralmente no início da infância. Neste campo, as guidelines seguidas são as referidas pela Associação Americana de Psiquiatria que, na $4^{\mathrm{a}}$ Edição do seu Manual de Diagnóstico Estatístico das Desordens Mentais ${ }^{5}$, explana que para se diagnosticar um caso de hiperatividade e défice de atenção, a perturbação tem de estar presente de forma persistente e perturbadora pelo menos em seis de dezoito sintomas, sendo que metade deles inclui problemas de atenção, problemas de hiperatividade e impulsividade (LOURENÇO, 2009).

A pesquisa tem demonstrado que a maioria dos jovens e crianças que apresentam dificuldades de aprendizagem possuem duplo diagnóstico, isto é, apresentam simultaneamente défice de atenção e hiperatividade (LOPES, 2009). Mas também têm mostrado que $80 \%$ das crianças diagnosticadas com PHDA apresentam dificuldades de aprendizagem. As dificuldades de aprendizagem e a PHDA parecem estar interligadas.

A PHDA pode manifestar-se sob a forma de três diagnósticos: um primeiro diagnóstico, designado como subtipo Misto, em que se denota a presença simultânea de agitação psicomotora e de falta de concentração; um segundo diagnóstico, designado como Predominantemente Desatento, mais difícil detetar, em que prevalece o défice de atenção; e um terceiro diagnóstico designado como

${ }_{5}^{4}$ Disponível em http://www.apdch.net/documentos/hiperactividade_infantil.pdf

${ }^{5} \mathrm{Na}$ língua original, referimo-nos ao DMS IV-TR (Diagnosis and Statistical Manual of Mental Disorders). 
Impulsivo, predominando neste caso um elevado nível de agitação psicomotora (COSTA ET AL, 2010).

As origens desta perturbação são ainda desconhecidas. Segundo os estudos já efetuados "pensa-se que haja influência da hereditariedade e da imaturidade neuroquímica dos centros cerebrais relacionados ao controle da atenção” (COSTA ET AL, 2010, p. 800). Já a forma de regular a PHDA é objeto de toda uma controvérsia entre a comunidade científica e a comunidade educativa, que foi objetivo do estudo que apresentamos. Se por um lado, existem alguns que defendem a administração exclusiva de fármacos, de outro lado outras perspetivas opõem-se a essa prática ou referem a necessidade de outras práticas de intervenção terapêuticas a nível de acompanhamento comportamental e cognitivo.

A forte oposição à administração da medicação deve-se à presença de metilfenidato na sua composição química, o que constitui um riscobenefício pois, embora pareça ser eficaz na regulação da perturbação, esta substância comporta riscos para o organismo destes jovens e crianças, podendo desencadear riscos cardiovasculares, riscos cerebralvasculares, riscos de distúrbios psiquiátricos, efeitos no crescimento e até leucemia, apesar deste último ainda ser um risco não totalmente confirmado (COSTA ET AL, 2010).

Em todas conjunturas históricas é possível encontrar críticas e controvérsias sobre a forma como estes comportamentos e estas identidades consideradas perturbadoras e desviantes em relação à cena social devem ser diagnosticados, categorizados e tratados, quer institucional, quer socialmente. É nosso objetivo expor as controvérsias em torno do diagnóstico e do tratamento do aluno com PHDA na instituição escolar. Para tal é preciso compreender como é que a escola tem percecionado estes jovens e que dispositivos têm sido acionados para regular o seu comportamento.

\section{A escola inclusiva e a Educação Especial}

No século XIX, a PHDA era confundida com estados de perversão, com deficiência mental e outros sintomas de perturbação mental grave (psicoses, esquizofrenias, psicopatias, entre outros) (LOURENÇO, 
2009). Desde meados do século XVI que assistimos a uma proliferação de hospitais psiquiátricos, hospícios e albergues destinados a estas populações consideradas como portadoras de deficiências hereditárias e incuráveis (ARANHA, 2008). Estas instituições não tinham como objetivo curar estas perturbações, mas ao invés disso, isolar os indivíduos com deficiências da restante sociedade.

É a este propósito que Goffman (2008) fala da experiência de estar institucionalizado como uma exclusão da vida em sociedade. Segundo este autor, a instituição total define-se como

[...] um local de residência e trabalho, onde um grande número de indivíduos com situação semelhante, separados da sociedade mais ampla por considerável período de tempo, leva uma vida fechada e formalmente administrada (GOFFMAN, 2008, p. 11).

Assiste-se nestas instituições a um processo de mortificação do eu (Goffman, 2008) e à atribuição de um determinado estigma, isto é, um atributo indesejado que fornece um «modelo de normalização» para os «normais», definindo certos limites para a «normalidade» (GOFFMAN, 1988). Apenas em meados dos anos '60 do século XX, se assiste a um processo de desinstitucionalização e a uma normalização da pessoa com deficiência, ou seja, "introduzir a pessoa com deficiência na sociedade, ajudando-a a adquirir as condições e os padrões de vida cotidiana o mais próximo do normal, quanto possivel" (ARANHA, 2008, p. 15).

No contexto escolar, os contributos de Carl Rogers para a pedagogia, em meados de 1960, provocam alterações profundas na forma como os professores devem percecionar e tratar a criança e os seus handicaps, pela sua abordagem centrada na ideia da pessoa, introduzindo assim uma lógica de uma escola mais inclusiva, respeitadora das individualidades e reparadora de handicaps tradicionalmente considerados irreversíveis (FERREIRA, 2002).

Na escola do passado, a disciplina imposta através de punição corporal - com recurso a instrumentos de tortura diversos - e do estímulo do medo no aluno eram instrumentos mobilizados para o adestramento dos corpos no espaço da sala de aula (FOUCAULT, 1996) e controlo dos handicaps físicos e cognitivos que faziam os alunos desviarem-se da norma escolar. Como afirma Durkheim: 
[...] existem pouquíssimas crianças predispostas a revoltarem-se abertamente contra o seu mestre, a afrontá-lo de frente (...). No entanto inúmeras são aquelas que são propensas a não se aplicarem, a distraírem-se (...)(1984, p. 266).

Este sociólogo francês, embora não defendendo o uso da violência física para impor a disciplina, salienta a importância do uso da punição dado que esta "impede que a regra perca a sua autoridade (...). Isto porque o que faz a sua autoridade é o fato de a criança a considerar inviolável" (DURKHEIM, 1984, p. 279-80).

As novas abordagens pedagógicas humanistas de Rogers de que falámos anteriormente fazem com que na opinião pública se tornem cada vez menos toleráveis as formas tradicionais de punição e regulação dos corpos e dos comportamentos dos alunos. Como defende Mendes (1995), hoje de forma menos punitiva e negativa é preferível reforçar os comportamentos desejados e reprimir os indesejados, mobilizando uma disciplina convidativa assente nas teorias do autoconceito, do otimismo, da intencionalidade, do respeito e da confiança. Nesta senda, ao mesmo tempo que o professor detém um estilo diretivo, controlando todos os acontecimentos em sala de aula, detém ao mesmo tempo um estilo facilitador, sendo um parceiro no processo de aprendizagem, flexível e partilhando o seu poder com a classe (MENDES, 1995). A escola torna-se ao mesmo tempo mais aberta, mais inclusiva e acolhedora de todos os alunos, isto é, o princípio fundamental da escola inclusiva consiste

[...] em todos os alunos aprenderem juntos, sempre que possível, independentemente das dificuldades e das diferenças que apresentem. Estas escolas devem reconhecer e satisfazer as necessidades diversas dos seus alunos, adaptando-se aos vários estilos e ritmos de aprendizagem, de modo a garantir um bom nível de educação para todos (SANCHES e TEODORO, 2006, p. 69-70).

Os alunos, antes estigmatizados como portadores de deficiência vêmse agora, nesta nova forma escolar moderna, com uma nova categorização com uma carga menos negativa do que a anterior. São doravante considerados como alunos com necessidades educativas especiais (alunos NEE), são objeto de todas as atenções e recebem igual tratamento e respeito tal como os restantes alunos (SANCHES e TEODORO, 2006). Trata-se de uma categoria que alberga um leque de crianças (invisuais, com problemas auditivos, com dificuldades de fala, 
portadoras de doenças raras, entre outras) entre as quais estão as que são diagnosticadas com Perturbação de Hiperatividade e Défice de Atenção.

A escola mune-se, então, de técnicos especializados que vêm coadjuvar os professores na reparação dos handicaps cognitivos, pedagógicos, físicos e sociais (Dionísio e Vieira, 2012) e também de outros dispositivos como os Serviços de Psicologia e Orientação (DIONÍSIO, 2009), os Gabinetes de Mediação e de Apoio ao Aluno e às Famílias (FEIJÃO, 2014) e os Departamentos de Educação Especial (FREITAS, 2013), todos eles reconhecendo a problemática das necessidades especiais em educação. É no contexto da criação do Departamento de Educação Especial nas escolas que aparecem os Professores de Ensino Especial, sendo eles os principais atores que vão apoiar os alunos com necessidades educativas especiais. Em Portugal, o Ensino Especial começa no século XIX com a criação de várias instituições espalhadas no país, mas só em 1916, se criou uma especialização para os professores e inicialmente apenas focada no trabalho com alunos com dificuldades auditivas (PEREIRA, 2008).

Em 1946, a educação especial chega pela primeira vez às escolas primárias com criação de classes compostas por esses alunos. Em 1960, estende-se às crianças invisuais e em 1970, estende-se a crianças com outros handicaps (motores, sensoriais e outros) (PEREIRA, 2008). É também nesse ano que o Ministério da Educação assume o setor da Educação Especial e cria Equipas de Ensino Especial Integrado nas escolas destinadas a apoiar os alunos com necessidades educativas especiais (PEREIRA, 2008). Por fim, em 2008, é talvez uma das medidas mais importantes neste âmbito, uma vez que se dá total reconhecimento a estes serviços educativos especializados salientando-se que as escolas devem incluir nos seus projetos educativos as adequações relativas ao processo de ensino, que acharem necessárias que permita a todas as crianças, especialmente às que têm necessidades educativas especiais, uma maior participação no âmbito das turmas em que se inserem (PEREIRA, 2008).

A escola pública é assim posta à prova de novos e múltiplos desafios: sinalizar os problemas dos alunos e encontrar respostas para os mesmos; procurar novas modalidades de tratamento dos handicaps, reconhecendo-os e agindo sobre eles atendendo à singularidade de cada aluno e à situação concreta; acolher e incluir na escola, todos os 
alunos, mas preservando a singularidade de cada um, em especial a singularidade dos que apresentam um handicap físico ou cognitivo que a escola se sente obrigada, em termos éticos, a reparar e/ou a neutralizar (DIONÍSIO, 2009).

\section{O que dizem as pesquisas sobre os alunos com PHDA? Breve roteiro em torno das perceções dos professores}

De entre as pesquisas já desenvolvidas acerca dos alunos com PHDA, encontramos um grande número advindo da área das ciências da educação, sobretudo dedicada a compreender as perceções dos professores sobre essa perturbação. Apesar de tudo, este conjunto de pesquisas é muito escasso e pouco consensual.

Segundo alguns autores, os professores apresentam-se pouco conhecedores relativamente à PHDA (KLEYNHANS, 2005; LOURENÇO, 2009; ESPADA, 2011), tendo essa falta de conhecimentos resultado em encaminhamentos e diagnósticos errados, no fornecimento de informações e conselhos errados às famílias e ainda numa nociva abordagem a estas situações e à sua resolução quando confrontados com elas no contexto de sala de aula (KLEYNHANS, 2005). No entanto, outras pesquisas (LOURENÇO, 2009; ESPADA, 2011) referem que os professores apesar de não terem conhecimentos sobre o assunto vão adquirindo informação ao longo do tempo e vão conseguindo aplicar estratégias para fazer face às situações que envolvem os alunos com PHDA nas salas de aula. Entre essas estratégias encontram-se a supervisão frequente do trabalho, a organização da sala de aula e a execução de tarefas curtas, bem definidas e bem sequenciadas (LOURENÇO, 2009; ESPADA, 2011).

No que respeita à identificação das causas para a ocorrência de tais comportamentos, existe uma divisão da parte dos professores. Uns não têm qualquer dúvida que existe um componente emocional associada à ocorrência destes comportamentos considerados desordeiros (JÚLIO, 2009; LOURENÇO, 2009), atribuindo como causas a não-aceitação das regras, as dificuldades de aprendizagem e ainda as dificuldades de relacionamento com os pares (Lourenço, 2009), defendendo a urgência e importância de uma intervenção psicológica (Júlio, 2009). Já outros professores defendem que a componente biológica é a única e principal responsável pelo desencadear dos comportamentos dos alunos com 
PHDA (Júlio, 2009), apresentando e descrevendo os comportamentos dos alunos em termos de sintomas mais do que em termos da experiência emocional, sendo também estes os professores que defendem o uso da medicação para reparar esta perturbação (Bradley, 2009). Contudo, também alguns professores apresentam nos seus discursos a ideia de que a medicação serve apenas para aliviar sintomas e não para ajudar a criança a fazer uma gestão eficaz do seu comportamento (BRADLEY, 2009).

Outras investigações salientam, no entanto, que há mais vantagem no uso combinado das intervenções terapêuticas e comportamentais, tendo-se registado, em várias escolas, melhorias ao nível do comportamento em sala de aula, do bem-estar dos alunos, das famílias e dos próprios professores (BATISTA, 2010).

\section{Apresentação e discussão de resultados}

\section{1- Das condições para a atuação sobre os alunos com PHDA: olhares dos professores e dos técnicos escolares sobre as políticas educativas e os apoios para o Ensino Especial}

No que diz respeito à legislação de apoio à Educação Especial, constatamos que os professores a olham de forma crítica dado não permitir envolver todos os casos de Perturbação de Hiperatividade e Défice de Atenção. Os professores admitem que "Consegue-se fazer um bom trabalho de equipa (...) acaba por conseguir adaptar determinadas tarefas" (Professor do Ensino Regular 1), mas que " $O$ problema é fazer com que essa legislação funcione bem. É esse o grande problema” (Professor do Ensino Regular 4)

Para os professores do ensino regular, a eficácia das políticas de ensino especial só é possível se a legislação não generalizasse os casos e se houvesse suficientes recursos humanos especializados para fazer face aos casos que existem na atualidade:

[...] há conjuntos de medidas [...] que não são suficientes para ajudar estes alunos no sentido em que são muito abrangentes, são muito gerais e a escola não tem possibilidade de os ajudar melhor, no sentido em que não há técnicos especializados neste 
momento para ajudar estes alunos (Professor do Ensino Regular $6)$.

Os professores do ensino especial, que são quem trabalha mais exaustivamente sobre estes casos de PHDA, tecem críticas ainda mais acérrimas em relação à legislação e às possibilidades de atuação sobre esses casos:

\begin{abstract}
A legislação sobre educação especial em Portugal é um pouco controversa. Não temos todos a mesma ideia do que é [...] nem os mesmos conceitos sobre o que é elegibilidade, quem é elegível [...] o que acontece com a legislação que está em vigor é que não existe nenhuma medida que de alguma forma $[\ldots]$ possa ajudar estas crianças [...) a legislação responde só a algumas questões, mas não a um todo que acaba por ser essencial nessas crianças (Professora do Ensino Especial 1).
\end{abstract}

Também os técnicos educativos têm uma opinião manifesta sobre este assunto. Embora concordem que a legislação trouxe um novo olhar sobre as crianças com necessidades educativas especiais e a sua inclusão escolar, concordam igualmente com o facto das políticas desenvolvidas neste âmbito não abrangerem todas as crianças e dar espaço a diferentes interpretações:

[...) a legislação em vigor promove a inclusão das crianças com necessidades especiais. Nestes casos são incluídas crianças com PHDA, mas não existe uma resposta eficaz e satisfatória para crianças com necessidades educativas especiais em todo o meio [...) os órgãos superiores, nomeadamente o Ministério e nomeadamente quem faz as leis porque não está no terreno não sabem o que se passa. Fazem apenas as leis, têm indicações do que se passa mas muitas dessas pessoas não conhecem o terreno, nunca lá foram, nem sabem do que se trata muito menos (Terapeuta Psicomotricista).

Há ainda a opinião, da parte dos técnicos de intervenção educativa, de que o próprio modus operandi em relação a estes alunos com necessidades educativas especiais vai contra o ideal de inclusão social proclamado pela nova forma escolar moderna:

[...) muitas vezes o apoio pedagógico personalizado é retirá-los da sala de aula. Às vezes acho que nem sempre é o mais indicado para o aluno porque está a sair do contexto do grupo de turma [...) não estamos a favorecer a integração dele e depois acabamos por, enquanto adultos, «negligenciar» [...) 
estratégias para a professora da turma trabalhar com aquele aluno porque retirá-lo é bem mais fácil [...) do que ter ali trinta alunos ou vinte e oito, que é o que acontece nas escolas públicas (Psicóloga Clínica).

Assistimos portanto à crítica, da parte de professores e técnicos educativos, a dois princípios de justiça escolar. Por um lado, a crítica ao modelo industrial (BOLTANSKI e THÉVENOT, 1991) que aponta para o paradigma da eficácia (DIONÍSIO, 2010) - que está no centro de debate público sobre a escola - reiterando-se a falta do investimento de dinheiros públicos na contratação de um maior número de técnicos especializados para acompanhar alunos com necessidades educativas especiais, mas também a falta de consenso relativamente a quem é elegível e não-elegível para beneficiar de tal acompanhamento e ainda da ineficaz preparação e formação de professores do ensino regular para sinalizar e desenvolver estratégias de trabalho com esses alunos. Por outro lado, a crítica ao modelo cívico (BOLTANSKI e THÉVENOT, 1991), remetendo para o paradigma da escola inclusiva e da igualdade de oportunidades e de tratamento (DIONÍSIO, 2013, 2014) em que a crítica se justifica pelo facto da legislação não abranger todos os alunos com necessidades educativas especiais e ainda ao modelo de intervenção personalizada sobre estes jovens que acaba por isolá-los da turma, tendo efeitos perversos ao nível da sua integração nas turmas e por desresponsabilizar os professores do ensino regular de intervirem sobre a situação.

\section{2- O processo de sinalização dos alunos com PHDA e as controvérsias em torno do diagnóstico}

A sinalização começa pelo professor: "logo no início do ano tivemos um longo uma formação por parte da equipa de ensino especial, portanto, a alertar-nos para essas situações. Qualquer professor pode sinalizar" (Professor do Ensino Regular 1). Todos os professores têm desde logo acesso a um impresso próprio, criado pelos Serviços de Psicologia e Orientação, onde devem escrever as motivações que os levam a pensar que o aluno tem PHDA. O registo da ocorrência é depois passado ao Conselho de Turma que se reúne para discutir o caso: 
(...) logo no início do ano ou no final do primeiro período é normalmente quando se faz a análise do comportamento de turma, fala-se dos casos mais complicados (...) [os professores] relatam a situação e como Conselho de Turma tomam a decisão de sinalizar o aluno ou não (...) (Professor do Ensino Regular $3)$.

No caso de decidirem sinalizar, o caso é remetido para a equipa de ensino especial. Muitas vezes se assiste a discordâncias entre famílias e professores quanto à decisão de sinalização do aluno como carecendo de acompanhamento educativo especial:

(...) há documentação, quando os pais não concordam, quando não são pais acessíveis. Nós preenchemos e fazemos a sinalização para ser entregue às professoras de ensino especial para elas analisarem com todas as opiniões do Conselho de Turma sobre esse aluno. Depois esse aluno é chamado para uma entrevista com os professores de ensino especial e depois são chamados também os pais para uma entrevista (Professor de Ensino Regular 4).

De seguida é feita uma avaliação pela equipa de professores de ensino especial, que posteriormente, se confirmada a sinalização, é remetida para o centro de saúde: “(...) depois levam a criança lá (...) e é feito o diagnóstico (...) e depois temos o feedback (...) e tentamos agilizar o processo em termos de inserção no Ensino Especial" (Professor do Ensino Regular 5). Em função do relatório médico é feito a posteriori um plano de intervenção e os professores do ensino especial dão indicações aos professores do ensino regular do tipo de adequações que podem fazer no seio da sala de aula. A psicóloga clínica dá o exemplo de como procede para efetuar o diagnóstico nas crianças e jovens com PHDA:

o diagnóstico é feito [...] com a ajuda dos pais através de questionários normalmente eu utilizo muito o questionário de Connors como o de Achenbach também... observação clínica no contexto de sala de aula é importante [...] estes questionários também há uma versão para os professores que é sempre fundamental e entrevista [...] tenho algumas sessões com as crianças e [...] além da observação da sala de aula das entrevistas com os pais, com os professores, com o alunos no contexto terapêutico e aqui já é possível fazer o diagnóstico e depois na altura sempre que havia necessidade porque nem sempre eu considero que seja importante haver medicação é encaminhado para a pedopsiquiatria ou para o médico de 
família para o hospital [nome hospital] que normalmente é onde as crianças pertencem [...] (Psicóloga Clínica).

No âmbito deste processo de sinalização não deixam de ser tecidas críticas por parte de profissionais do ensino e técnicos educativos, o que é expectável já que todos os profissionais já anteriormente haviam manifestado um sentimento de descontentamento face à indefinição da legislação sobre quem é ou não elegível como aluno com necessidades educativas especiais. Os professores de ensino especial fazem, desde logo, uma crítica aos professores do ensino regular pelas informações que fornecem nas fichas de referenciação que chegam aos departamentos do ensino especial:

(...) às vezes as fichas não trazem nada! «Ai, ele é muito distraído e perturba»! Hum, hum e isso significa o quê? Que está a olhar para os pássaros lá fora, que perturba e atira a cadeira à cabeça do vizinho ou que perturba porque deixa cair o lápis? Quer dizer (...) uma informação que não diz muito, portanto, procuramos aí recolher informações, discutir em equipa (...) (Professora de Ensino Especial 2).

Muitos destes professores têm a convicção de que "o grande problema (...) é os professores não conseguirem distinguir o que é a indisciplina do que é a hiperatividade e perceberem a diferença entre um e outro" (Professor do Ensino Especial 2) afirmando que, "às vezes até (...) pode-se cair já um bocadinho no exagero que às vezes por qualquer aluno que seja mais irrequieto ou isso. Vêm logo com um relatório que ele às tantas até pode ter um PHDA" (Professor do Ensino Especial 5). Contudo, também se reconhece que

Há outros professores muito sensibilizados e muito virados para a diversidade e para perceberem que nós de facto que somos todos diferentes e evidentemente que há meninos que têm algumas dificuldades mas que é importante investir neles e é importante dar-lhes ferramentas (Professor de Ensino Especial $3)$.

Um dos professores de ensino regular dá o seu testemunho:

Há uns anos atrás, sou-lhe sincero, houve uma altura em que achei que à mínima situação, ocorrida numa sala de aula, eram logo rotulados como hiperativos e mandavam-nos para o psicólogo e vinham de lá com Ritalina. Sou-lhe sincero, há uns anos atrás senti isso. Houve aí uma fase em que parecia óbvio e às vezes até tinha receio de sinalizar o que quer que fosse 
porque parecia que era tudo hiperativo (Professor do Ensino Regular 1).

Mais uma vez denota-se as críticas dos professores assentes no modelo industrial (BOLTANSKI e THÉVENOT, 1991) e no paradigma da eficácia (DIONÍSIO, 2010), denunciando a falta de competência e formação dos professores no diagnóstico das situações envolvendo alunos com hiperatividade e défice de atenção: "somos todos especialistas e depois chega a escola e ninguém percebe metade. Acho que francamente, a formação especializada entrou pelas ruas da amargura" (Professora de Ensino Especial 3).

Mas, não são apenas os professores que são alvo de críticas. Também a comunidade médica é objeto de profundas depreciações:

Os médicos parecem que têm cópia lá por baixo da secretária que é o relatório de todos miúdos, então sai tudo igual! Se nós começarmos a comparar os relatórios são praticamente todos iguais, não pode ser! (...) E quando nós pedimos ajuda (...) não é para darem um relatório exatamente igual ao aluno $\mathrm{X}$ ou $\mathrm{Y}$ porque não vale a pena. Nós precisamos de conhecer é aquele aluno. É aquele aluno que estamos a trabalhar. Eu sei que um hospital não é um fábrica (...) eu sei que tem de haver tempo para ser analisada a criança, mas é contra isso que temos que lutar e fazer perceber à nossa sociedade que não pode ser (...) (Professor de Ensino Regular 4).

(...) acho que se acabou por se criar um rótulo muito fácil que de alguma forma é mais fácil depois de lidar e depois dar um comprimido a uma criança que seja muito agitada do que tentar perceber as razões ou todas as dimensões dessa criança e tentar perceber exatamente o que se passa (...) acho que deveria de haver mais cuidado nestas avaliações (...) (Professor de Ensino Especial 4).

a comunidade médica penso que também por questões de negócio (...) existe essa facilidade em facilmente, e passo a expressão, realizar a prescrição farmacológica e por aí resolver ou tentar resolver o problema o que muitas das vezes não é o comportamento mais adequado (...) (Terapeuta Psicomotricista).

As críticas dos professores à comunidade médica também assentam num paradigma da eficácia (DIONÍSIO, 2010), justificando a incompetência profissional de muitos médicos aquando da elaboração 
de diagnósticos: "alguns médicos de familia, sobretudo os mais velhos, em termos de idade e em termos de experiência, muitos deles não estão alertados, preparados para trabalhar de forma melhor com estas crianças" (Professor do Ensino Regular 6).

As próprias clínicas privadas são alvo de crítica ainda mais acérrima: "as clínicas que existem para ai tratam-na [a PHDA] muito mal, tratam-na pessimamente. É uma forma fácil de se ganhar dinheiro (...) e se venderem medicamentos" (Professor de Ensino Especial 2). Para além da crítica na base da gramática industrial da eficácia, é também recorrente no seu discurso o uso de uma gramática mercantil (BOLTANSKI e THÉVENOT, 1991), denunciando a definição do diagnóstico com a finalidade de gerar lucros económicos.

A falta de consenso nos diagnósticos parece estar relacionada com uma comunidade científica que não é totalmente clara relativamente ao problema:

Relativamente à PHDA existe por vezes uma grande disparidade e até algum conflito em relação ao diagnóstico porque não é um diagnóstico fácil de fazer e porque muitas das características, sinais e sintomas da patologia se confundem com sinais e sintomas de outras patologias que poderão ter expressões muito semelhantes (...) a comunidade científica tem opiniões muito divergentes ...a comunidade terapêutica $(\ldots)$ tem uma visão mais centrada na criança e em todo o seu comportamento e tem em conta as condições e as condicionantes que poderão estar adjacentes à problemática (...) a comunidade para a literatura, para a investigação poderá não estar tão desperta se não esteve em campo, se não esteve em contato direto com a criança (Terapeuta Psicomotricista).

(...) é daquelas perturbações que acaba por ser pouco clara até na própria identificação do que é, até na própria identificação a nível clínico (...) tudo diz e portanto há aquela fronteira (...) uma comunidade científica que estudou, que investiga, que está pronta a mostrar evidências de experiências, de investigações ...isso é uma coisa que nos chega pouco no dia-a-dia (Professora de Ensino Especial 3).

Esta indefinição acerca do que é a PHDA tem expressão nas representações dos professores e dos técnicos educativos sobre os alunos que julgam ter essa perturbação. 


\section{3- Representações sociais sobre os alunos com PHDA}

Os professores do ensino regular desenvolvem sobre os alunos com PHDA representações sociais de caráter depreciativo: "[...] não conseguem estar [...] atentos à aula, são alunos que têm alguma dificuldade em se concentrarem e acompanharem o ritmo da aula [...] acaba por perturbar também o bom funcionamento das aulas" (Professor do Ensino Regular 1), têm "[...] mau comportamento [...] agressivos [...] mal educados, de insultarem-se uns aos outros [...]"(Professor do Ensino Regular 5) e "[...] quando os casos são muito extremos e são descontrolados acontece que estes meninos têm uma tendência para serem marginais e para perturbarem muito a escola e faltarem e terem comportamentos de risco [...]" (Professor de Ensino Regular 2).

Segundo os professores, estes alunos "[...] perdem-se dispersam-se começam a olhar no vazio brincam com todo o tipo de material escolar [...]" (Professor de Ensino Regular 3) e "têm graves problemas de comportamento eles não sabem estar em sala de aula [...] são alunos com uma falta de disciplina muito grande [...]" (Professor de Ensino Regular 4). Referem ainda que não conseguem "[...] se manter quietos durante tempo suficiente para adquirirem as aprendizagens [...] e levam a que nós professores tenhamos que estar constantemente a interromper a aula para chamar à atenção" (Professor do Ensino Regular 6). Há aqui uma representação social em que se torna difícil discernir os alunos PHDA e os alunos indisciplinados, levando-nos para discursos anteriores em que se afirmava que de facto os professores, especialmente de ensino regular, têm dificuldades em fazer esta distinção.

Quanto aos professores do ensino especial, estes referem que a PHDA, “[...] é uma patologia [...] que tem a ver portanto com uma falta de atenção por parte do aluno e que pode ou não ter uma agitação motora associada [...]" (Professora de Ensino Especial 5); sendo que "[...] eles são alunos que interrompem muitas vezes. Tudo lhes cai ora cai! Ora cai o lápis, ora cai a borracha, ora viram-se para a frente ora viram-se para trás [...]" (Professora do Ensino Especial 5). E de facto todo o seu discurso associa os alunos a problemas de 
comportamento derivado ao facto de serem portadores de uma patologia e não ao facto de serem indisciplinados:

[...] às vezes costumo dizer na brincadeira que há meninos que não são hiperativos que são híper malcriados [...]. Portanto nem todos os alunos que têm comportamentos desajustados. São hiperativos, portanto há que ter um certo cuidado com isso [...] são meninos que são malcriados que não têm regras não têm normas $[\ldots]$ o que é diferente de um aluno ou de uma criança que tem hiperatividade [...] está cada vez mais provado que tem a ver com a parte neurológica [...] (Professora de Ensino Especial 4).

Conseguimos, nos discursos de professores do ensino regular e professores do ensino especial, perceber diferenças em relação à forma como constroem a identidade de um aluno com PHDA. Resta percebermos se esta insistência da parte dos professores de ensino regular em rotular os alunos hiperativos como indisciplinados têm consequências ao nível da intervenção em sala de aula, nomeadamente podendo isso traduzir-se em processos de estigmatização em relação a outros colegas, de exclusão da turma, entre outros.

Ao nível da representação social dos técnicos educativos podemos ver que ambos, tal como os professores de ensino especial, têm uma clara perceção do PHDA, dado que têm formação na área:

a criança que tem PHDA, na minha opinião, tem algum comprometimento em manter a sua atenção sendo que pela problemática dispersa a sua atenção sobre vários focos e é esse mesmo o grande foco da PHDA é a criança conseguir prestar atenção de forma seletiva e de forma mantida num mesmo estímulo e não sobre vários estímulos ao mesmo tempo aos quais depois não consegue fazer esse tratamento de informação organizado e o qual não consegue ser eficaz porque [...] tenta dar atenção a tantos estímulos que a nenhum deles consegue dar uma atenção de qualidade (Terapeuta Psicomotricista).

(...) claramente a criança apresenta uma irrequietude muito demarcada mesmo com medicação, grandes dificuldades de atenção [...], de se concentrar e de manter a atenção por grandes períodos de tempo e uma fragilidade [...] psicoafectiva muito grande que depois acaba por ter repercussões na aprendizagem [...] (Psicóloga Clínica). 
Depois de observarmos os contrastes nas representações de professores e técnicos educativos, resta-nos observar como é feita a intervenção junto destes alunos no quotidiano escolar.

\section{4- A intervenção junto dos alunos com PHDA: estratégias e dilemas no controlo dos comportamentos em sala de aula}

Em geral, todos os professores, quer do ensino regular quer do ensino especial, estão de acordo com o facto de que a presença de aluno com PHDA tem impacto na dinâmica da sala de aula. Os professores de ensino regular são os que expressam com mais recorrência os dilemas na gestão das suas salas de aula, advogando que os alunos "[...] parecem mesmo que estão numa realidade tipo à parte [...]" (Professor de Ensino Regular 3);

(...) qualquer aluno que se distraia com a menor das facilidades é no geral uma fonte de problemas digamos assim problemas para ele próprio e problemas para os outros também [...] eles não são os únicos alunos na turma e nós não podemos estar constantemente a chamá-los à atenção não podemos passar noventa minutos a chamar à atenção um único aluno [...] levanos obrigatoriamente a alterar e a diversificar as estratégias dentro da sala de aula/ nem sempre nos é possível fazer isso primeiro porque precisamos de expor um determinado assunto que pode demorar entre dez a vinte minutos para alguns alunos já é difícil tomar atenção a vinte minutos depois aquilo que eles fazem como não tomaram atenção não conseguem fazer e nós nem sempre conseguimos explicar-lhes só a eles de maneira a que eles percebam porque estão os outros todos também [...] (Professor do Ensino Regular 6).

os grandes problemas às vezes é a motivação penso que um aluno quando está motivado qualquer professor consegue passar a sua mensagem e eles conseguem aprender com muita facilidade [...] (Professor do Ensino Regular 3).

Os professores do ensino especial estão de acordo com as observações apresentadas pelos professores do ensino regular, admitindo que "[...] os conteúdos curriculares que têm que ser dados e administrados e isto é uma luta que os professores têm e que os alunos acompanham ou não [...]" (Professor do Ensino Especial 3). Entre os técnicos educativos também há acordo sobre a influência na dinâmica da sala 
de aula, mas argumentam que os professores e as escolas não estão preparados para acolher os alunos com necessidades especiais de educação nas suas turmas:

[...] considero que o sistema de ensino nomeadamente intra-sala de aula não está preparado para dar resposta a um número alargado de crianças com necessidades especiais neste caso com PHDA porque o professor é só um, as turmas neste momento são enormes são acima de vinte e cinco crianças no mínimo e considero que a atenção que deverá ser dada de forma mascarada de forma especial vá lá não poderá ser o mais satisfatório porque não há meios para isso e porque o professor não consegue dividir a sua atenção da forma que ele possivelmente gostaria (Terapeuta Psicomotricista).

No respeitante à partilha ou não dos currículos académicos, grande parte dos professores reconhece a necessidade de adaptações a estes alunos com necessidades educativas especiais, propondo mesmo que o aluno seja retirado da sala de aula e tenha um acompanhamento personalizado:

[...] eles precisam que nós estejamos ali junto deles sentados a ajudá-los e dentro da sala de aula nós temos mais vinte e seis ou vinte e sete portanto não podemos estar única e exclusivamente com aqueles alunos [...] e eu quando digo retirá-los é saírem da sala de aula onde está a turma toda e irem para um gabinete de trabalho trabalhar com o técnico ou com um qualquer professor mesmo que seja a fazer o mesmo trabalho da turma simplesmente não têm o foco de atenção mais disperso porque não tem os colegas, estão mais concentrados no seu trabalho, mudam de ambiente, mudam de professor, de adulto com quem estão a trabalhar e acaba por ser um pequeno intervalo um pequeno descanso que depois os ajuda também a retomar novamente o seu trabalho [...] (Professor de Ensino Regular 6).

Os professores do ensino especial são unânimes e defendem que estes alunos devem manter-se no currículo comum, que deve sofrer pequenas alterações de modo a adaptar-se às necessidades educativas destes jovens com PHDA. Não há necessidade de existência de um currículo paralelo específico a não ser como último recurso, caso o aluno não consiga prosseguir nos estudos com essas pequenas alterações curriculares, salientando igualmente as consequências negativas: 
[...] realmente se uma criança que nós percebemos que não consegue de forma nenhuma nem com estas adequações chegar à conclusão das competências finais de ciclo então aí é que há mesmo a necessidade de partilhar outro currículo/ de ter outro currículo feito à sua medida, o problema é que fecha imensas portas depois pronto essa é que é a grande questão e portanto temos sempre imenso cuidado nesse sentido (Professor de Ensino Especial 1).

Da parte dos técnicos educativos, a psicóloga clínica acredita que a partilha de currículo é "[...] extremamente adequado", mas o técnico psicomotricista discorda: "[...] o currículo integralmente igual semelhante ao das crianças como ditas normais [...] não creio que seja vantajoso".

Mais uma vez, constatamos que as críticas dos professores e técnicos se ancoram em duas gramáticas que se entrecruzam: a gramática industrial assente no paradigma da eficácia e na gramática cívica assente na inclusão escolar (BOLTANSKI e THÉVENOT, 1991; DIONÍSIO, 2013; 2014). Por um lado, é preciso ser-se eficaz na obtenção de resultados escolares, mas por outro, é preciso ser-se inclusivo, procurando chegar a todos os alunos e dar a todos as mesmas oportunidades de chegar a um objetivo comum.

Mas que estratégias mobilizam estes profissionais para controlar os comportamentos dos alunos com PHDA? Os professores salientam que [...] não há método nenhum eficaz [...]" (Professor de Ensino 3) que resulte com todos os alunos. Mas que existem algumas estratégias que utilizam com alguma frequência. Uma dessas estratégias é pedirem que o aluno saia da sala de aula e vá à rua apanhar ar ou ir à casa de banho lavar a cara e respirar fundo. Outra estratégia consiste em pedir ao aluno para ficar sentado na mesa do professor por ser mais fácil chamá-lo à atenção, seja com um toque no braço, seja oralmente, minimizando a perturbação que o aluno em questão pode provocar na sala de aula. Outra estratégia consiste em manter os alunos ocupados e adaptar os exercícios para que não dispersem tanto a atenção, e ainda pedir-lhes ajuda para pequenas atividades que normalmente são da responsabilidade do professor, como por exemplo distribuir folhas de exercícios, acender a luz da sala de aula, apagar o quadro, entre outras, resultando isso num gasto maior de energias. 
Os Professores de Ensino Especial concordam que é necessário criar estratégias dentro da sala de aula para conseguirem controlar os comportamentos e que "[...] para alguns alunos determinadas estratégias funcionam, para outros as mesmas estratégias não funcionam de maneira nenhuma [...] qualquer estratégia é boa desde que resulte [...]” (Professor de Ensino Especial 2). As estratégias mais comuns são a "[...] organização do espaço, organização do tempo e organização dos conteúdos [...]” (Professor de Ensino Especial 3).

A Psicóloga Clínica defende que a melhor estratégia será a de mantê-lo próximo para que seja possível, sempre que haja distração, “[...] fazer [...] um toque no braço [...] ou um toque na mesa [...]” e manter os alunos longe das janelas, portas de forma a que não se distraiam com os colegas e ter apenas o necessário em cima da mesa.

Contudo, também se reconhece que alguns professores apresentam falhas na forma como agem nessas situações: “[...] às vezes já por cansaço do adulto por chamar uma, duas, três, quatro vezes à atenção acaba por o deixar de parte [...]"'(Professor do Ensino Regular 3); "[...] quando destabiliza: 'vai correr para o intervalo porque aqui estas a incomodar' (Professor do Ensino Regular 4); “[...] muitas vezes eles são colocados fora da sala de aula não digo injustamente porque eles fazem asneiras claro, não é a questão de ser injusto ou não mas é a questão de tentar relevar e as pessoas não sabem, nós não temos formação para isso"'(Professor do Ensino Regular 5).

O trabalho com as famílias destes alunos também não se adivinha um trabalho fácil, dado que as famílias não conseguem aceitar a diferença dos filhos e chegam mesmo a negligenciar a necessidade de acompanhamento:

“[...] a grande maioria dos encarregados de educação e das famílias não dão a devida atenção a essas crianças e daí não as acompanharem, daí não as levarem ao médico, não estarem minimamente atentos para essas problemáticas" (Professor Ensino Regular 5).

Por outro lado, ocorrem também situações em que as famílias são interventivas e tentam desculpar o mau comportamento dos filhos afirmando que estes sofrem de défice de atenção: 
[...] às vezes os pais para defenderem os filhos e porque sabem que há sempre adequações para determinados meninos às vezes o filho é um mal educado e o que é que acontece: "vou dizer que ele tem dificuldades de atenção" e é quando ele não quer aprender e que não quer fazer alguma coisa "ah vou à escola e digo que o miúdo tem défices de atenção" [...] agora está na moda os meninos serem NEE's pronto por tudo e mais alguma coisa [...]" (Professor do Ensino Regular 3).

Ainda há caso das famílias que ignoram o problema mesmo quando alertados pelos professores, encarando como um estigma essa patologia que afeta os comportamentos dos seus filhos e evitando pensar nela a todo o custo:

Há pais que [...] acham que os alunos merecem só um par de estalos e que não é nada [...] muitas vezes também há algum estigma negativo por parte da sociedade e os pais, os encarregados de educação nem sempre referem que os filhos têm estes problemas [...] por isso o aluno vai andando dia após dia com o problema sem que ele seja resolvido (Professor do Ensino Regular 6).

[...] há aquelas famílias que acham que não é nada e que as coisas se vão resolver e que não é e não ouvem ninguém e pronto e há aquelas famílias que realmente estão preocupadas e querem ouvir e tentam perceber e fazem as perguntas que são efetivamente relevantes [...] (Professor de Ensino Especial 1).

Os técnicos educativos vão mais longe afirmando que muitas vezes são estas famílias que encaram a hiperatividade como um estigma que desrespeitam e desmotivam as crianças, mas ao mesmo tempo se reconhece que para as famílias acaba por ser frustrante e desgastante conviver com estas crianças diariamente:

[...] há muitas famílias que não respeitam a criança não respeitam a condição que a criança tem tentam julgá-la ou tentam vê-la como alguém que é mal-educado, que não sabe estar, que não sabe se comportar e muitas delas fazem uso abusivo [...] do castigo da punição de palavras menos próprias e desmotivantes para aquela criança [...] acredito também por outro lado [...] que não deve ser nada fácil enquanto pai enquanto mãe enquanto irmão [...] estar todos os dias com alguém que ou não está ali se for uma PHDA com supra de défice de atenção, ou então que não para quieto que tem os chamados bichos-carpinteiros como muitas vezes se podem ouvir por aí erradamente [...] e acredito que seja frustrante e que por vezes seja também desgastante para a família [...] (Técnico Psicomotricista). 
Por outro lado, a psicóloga clínica explica a forma como algumas famílias falam do problema de uma forma leve, consultando médicos para medicarem os seus filhos e como fazem um uso abusivo dessa medicação:

[...] são raros os pais que dão depois acabam por voltar atrás porque sentem que têm efeitos secundários adversos, depois voltam a dar porque percebem que depois há uma pressão por parte da escola, dos professores de turma, normalmente mais por parte dos professores de turma [...] e depois voltam a dar depois deixam de dar, e depois há outros que dizem: «não não vamos voltar a dar» (Psicóloga Clínica).

Esta técnica educativa é aliás muito crítica em relação a esta abordagem, dizendo que esta opção leva muitas famílias a descurar a intervenção comportamental:

[...] só a farmacologia não é suficiente, aliás é só um tapar [...] é só dar ali um calmante e depois não há estratégias como a terapia que eu considero fundamental e o acompanhamento psicológico e também a intervenção familiar que também é fundamental (...) nem sempre é necessário e acho que muitas vezes nos encostamos um bocadinho atrás disso [...] achar que os medicamentos fazem milagres, mas aí seríamos um bocadinho uns patetas alegres não é? Tomávamos a medicação e ficávamos alienados do mundo e não é isso que acontece e o facto de se tomar medicação descuida-se de outro tipo de intervenções mais relacionais e muito mais benéficas só que levam é mais tempo em manifestar do que a medicação [...] a criança toma a medicação e vem logo mais apática nessa manhã e uma terapia não há logo esta causa-efeito (Psicóloga Clínica).

\section{Da mesma opinião é o Terapeuta Psicomotricista:}

Defendo que a farmacologia neste caso seja abordada como psicofarmacologia/ concordo que nalguns casos deva ser prescrita a medicação mas sempre em trabalho conjunto com toda uma intervenção terapêutica [...].

Já os Professores de Ensino Regular variam na sua opinião em relação ao uso da medicação. Se uns consideram que "as medicações não ajudam em nada, ainda os põem mais apáticos" (Professor do Ensino Regular 2), outros consideram que a medicação é uma boa solução já que "[...]se estão medicados conseguem ter uma atenção maior" (Professor do Ensino Regular 3). Dos professores que concordam com 
o uso da medicação, salientam desde logo modificações no comportamento dos alunos com PHDA:

[...] é ótimo que eles tomem a medicação porque eles próprios em geral se sentem muito melhor [...] são capazes de aprender e sabem que são capazes de fazer as mesmas coisas tal e qual os outros por outro lado também se sentem incapazes de o fazer por si próprios e a medicação ou vem completamente alterar a sua forma de estar dentro da sala de aula e ajuda-os também a passarem um patamar mais acima e a ultrapassar dificuldades que eles tinham e que lhes permite alcançar metas, alcançar objetivos que de outra forma não seriam capazes de o fazer (Professor do Ensino Regular 6).

Os Professores do Ensino Especial são mais consensuais na sua opinião em relação à medicação como forma de regulação do comportamento de alunos com PHDA. Para estes professores, a medicação faz sentido para casos mais complicados, mas sempre fazendo-se acompanhar de uma intervenção de tipo comportamental:

[...] medicação para esses casos extremos [...] mas juntamente com uma terapia que de alguma forma possa equilibrar estas duas questões porque o que o medicamento na minha opinião vai fazer é mascarar efetivamente [...] outras questões que são mais importantes que são por exemplo as questões emocionais e acho que só dar o medicamento e não fazer de alguma forma um acompanhamento terapêutico para que esses hábitos e vícios fiquem, então a medicação não está basicamente a fazer nada na minha opinião (Professora de Ensino Especial 1).

Também estes professores reconhecem que os alunos "estão muito mais calmos desde que tomam a medicação" (Professora de Ensino Especial 3), embora se mostrem preocupados com o uso abusivo desta medicação porque "há muita controvérsia e porque se fala muito dos efeitos secundários desta medicação" (Professora de Ensino Especial 5). Há que aferir esta questão e efetuar a medicação apenas aos casos que realmente têm necessidade desta medicação, chamando-se assim a atenção para a necessidade de eficácia na ação médica aquando do ato de diagnosticar a patologia: "isso é uma questão clínica que tem de ser aferida e discutida com os médicos (...) estou a dizer é que aparecem tantos, tantos, tantos casos que muitos deles [risos]... pois" (Professora do Ensino Especial 3). 
Também neste caso as gramáticas da eficácia e da inclusão justificam o uso da medicação: aumenta o rendimento escolar dos alunos, contribui para aumentar a autoconfiança do aluno e a sua integração na classe e também para o bem-estar da classe e do professor. De entre aqueles que estão contra o uso da medicação encontramos discursos que entrecruzam a gramática da eficácia com a gramática doméstica (BOLSTANKI e THÉVENOT, 1991), pois se por um lado, argumentam que o uso de medicação não resolve o problema da PHDA, na medida em que apenas deixa os alunos apáticos, por outro, isso constitui-se como uma forma das famílias desresponsabilizaremse do dever de acompanhamento do seu educando e muitas vezes de desresponsabilizarem os alunos do incumprimento da sua missão na escola.

\section{Considerações Finais}

Este estudo revelou-se importante não só para alertar para as controvérsias sobre o diagnóstico e o tratamento da Perturbação da Hiperatividade e Défice de Atenção nas escolas, mas também para sensibilizar para os dilemas que profissionais do ensino e técnicos enfrentam no seu quotidiano de trabalho.

Identificou-se a inadequação da legislação existente, muitas vezes difícil de colocar em prática por aqueles que trabalham na área do ensino especial, pelo facto de, na comunidade científica e médica, não estar definido consensualmente o que se entende por aluno com necessidades educativas especiais, podendo alguns dos alunos que se encontram nessa situação serem excluídos dessa condição e não beneficiarem do apoio personalizado a que têm direito. Também se sente, pelos profissionais da área, que existe uma falta de apoios financeiros traduzindo-se isso, na impossibilidade de contratação de mais técnicos educativos especializados para tratar os casos de hiperatividade e défice de atenção que estão a aumentar na escola.

A falta de informação consensual e de formação de alguns professores, sobretudo do ensino regular, leva a sinalizações incorretas e a algumas confusões na distinção de alunos indisciplinados e alunos hiperativos, levando muitas à estigmatização destes últimos e à intenção de exclusão da sala de aula por não conseguirem lidar com os efeitos da 
perturbação. A dificuldade de trabalho com as famílias pela sua nãoaceitação da sinalização ou da sua negligência em relação à situação do aluno e ainda os diagnósticos médicos não consensuais que fazem aumentar drasticamente o número de crianças hiperativas e com défice de atenção são outros dos dilemas com que se confrontam professores e técnicos educativos no seu quotidiano.

Podemos observar como os profissionais mobilizam um conjunto de justificações plurais que engrandecem os seus pontos de vista acerca daquilo que considerem injustono diagnóstico e o tratamento da PHDA nas escolas portuguesas (BOLTANSKI e THÉVENOT, 1991). Todos os professores e técnicos educativos se fazem valer, sobretudo, de duas gramáticas nos seus julgamentos de justiça escolar: de um lado a gramática industrial assente no paradigma da eficácia, advogando a necessidade de ser eficaz nos diagnósticos e nas estratégias de intervenção sobre os alunos com PHDA; de outro lado, a gramática cívica assente no paradigma da inclusão, visando a igualdade de oportunidades e a integração dos alunos com PHDA nas turmas de ensino regular. A escola contemporânea parece, assim, exigir, a todo o custo, a concretização de uma inclusão eficaz (DIONÍSIO, 2014).

\section{Referências}

ARANHA, Maria Salete Fábio. Paradigmas da relação da sociedade com as pessoas com deficiência. Marília: UNESP, 2008

BATISTA, Maria Graça. Perturbação de Hiperatividade e Défice de Atenção em contexto escolar: estudo exploratório das perceções dos professores sobre o impacto comportamental de crianças com PHDA em escolas do $1^{\circ}$ ciclo. Dissertação de Mestrado - Educação Especial, Faculdade de Motricidade Humana da Universidade Técnica de Lisboa, 2010

BOLTANSKI, Luc; THÉVENOT, Laurent. On Justification: economies of worth. Princeton: Princeton University Presses, 1991.

BRADLEY, Jess. Children and teachers' perceptions of ADHD and medication, Tese de Doutoramento - Psicologia Educacional, Faculdade de Ciências Médicas, Saúde e Vida da Universidade de Southampton, 2009.

COSTA, Catarina et al. Perturbação de Hiperatividade e Défice de Atenção: revisão teórica e áreas de intervenção. VII SIMPÓSIO 
NACIONAL DE INVESTIGAÇÃO EM PSICOLOGIA. Minho: Universidade do Minho, 4 a 6 de Fevereiro de 2010.

DIONÍSIO, Bruno. Orientação no plural: promessas e limites do serviço público de orientação escolar, Tese de Doutoramento Sociologia, Faculdade de Ciências Sociais e Humanas da Universidade Nova de Lisboa, 2009.

O paradigma da escola eficaz: entre a crítica e a apropriação social. Sociologia: Departamento de Sociologia da FLUP, Porto, Faculdade de Letras da Universidade do Porto, vol. XX, 2010, p. 305-316.

Como a escola (mal) trata as pessoas? Promessas e limites das políticas de reconhecimento escolar. V ENCONTROS DE PORTALEGRE. Portalegre: Escola Superior de Educação do Instituto Politécnico de Portalegre, 17 de Setembro de 2013.

Sobre a condição de jovem intervencionado: pode a preocupação com o risco tornar-se insuportável?.VI ENCONTROS DE PORTALEGRE. Portalegre: Escola Superior de Educação do Instituto Politécnico de Portalegre, 8 a 10 de Setembro de 2014.

DIONÍSIO, Bruno; VIEIRA, Maria Manuel. O lugar e o trabalho dos profissionais do social em Escolas TEIP. In: LOPES, João Teixeira (org.). Escolas Singulares: estudos locais comparativos. Porto: Edições Afrontamento, 2012, p. 82-98.

DURKHEIM, Émile. Educação Moral, São Paulo: Melhoramento, 1984.

ESPADA, Cláudia. Atitudes dos Professores do $\mathbf{1}^{\circ}$ Ciclo face à inclusão dos alunos com Perturbação de Hiperatividade e Défice de Atenção. Dissertação de Mestrado - Ensino Especial, Guarda, ESEAG, 2011.

FEIJÃO, João. Entre professores e profissionais de mediação: que capacidade de coordenação na reparação da desordem escolar? In: CONGRESSO PORTUGUÊS DE SOCIOLOGIA, 8, 2014, Évora. 40 Anos de Democracia (s): progressos, contradições e prospetivas. Évora: Associação Portuguesa de Sociologia.

FERREIRA, Berta. A aprendizagem na perspetiva humanista de Carl Rogers. In: LA ROSE, Jorge et al (org). Psicologia e Educação: o significado do aprender. Porto Alegre: EDIPUCRS, 2002.

FOUCAULT, Michel. Vigiar e Punir, Vozes: Petrópolis, 1996. 
FREITAS, Nélia. Crianças e Jovens com Perturbação de Hiperatividade e Défice de Atenção: Controvérsias em torno do diagnóstico e do tratamento. Dissertação de Mestrado - Sociologia, especialidade em Comunidades e Dinâmicas Sociais, FCSH-UNL, 2013.

GOFFMAN, Erving. Estigma: notas sobre a manipulação da identidade deteriorada. Rio de Janeiro: LTC, 1984.

Editora Perspetiva, 2008.

Manicómios, Prisões e Conventos. São Paulo:

JÚLIO, Ana Rita. Representações acerca da Perturbação de Hiperatividade e Défice de Atenção. Dissertação de Mestrado Educação Especial, Faculdade de Psicologia e Ciências da Educação da Universidade de Coimbra, 2009.

KLEYNHANS, Sandra. Primary school teachers' knowledge and misperceptions of ADHD. Dissertação de Mestrado - Psicologia Educacional, Univeridade de Stellenbosch, 2005.

LOPES, Ana. Dificuldades de aprendizagem específicas e desordem por défice de atenção e hiperatividade: um estudo single-subject sobre monitorização da atenção. Dissertação de Mestrado - Ensino Especial, especialidade em Dificuldades de Aprendizagem, Universidade do Minho, 2009.

LOURENÇO, Maria Isabel. Hiperatividade e Défice de Atenção em contexto escolar: estudo comparativo das perceções e atitudes de professores do $1^{\circ}, 2^{\circ}$ e $3^{\circ}$ Ciclos do Ensino Básico. Dissertação de Mestrado - Ensino Especial, Faculdade de Motricidade Humana da Universidade Técnica de Lisboa, 2009.

MENDES, Francisco. A indisciplina em aulas de educação física no $6^{\circ}$ ano de escolaridade. Tese de Doutoramento - Ciências do Desporto, especialidade em Pedagogia do Desporto, Universidade do Porto, 1995.

PEREIRA, Maria Júlia. Atitude estratégica do professor face à hiperatividade. Dissertação de Mestrado - Ciências da Educação, Faculdade de Ciências Sociais da Universidade Católica, 2008.

SANCHES, Isabel; TEODORO, António. Da integração à inclusão escolar: cruzando perspetivas e conceitos. Revista Lusófona de Educação. № 8, 2006, p.63-83. 